\title{
Sistem Pendukung Keputusan Pemilihan Kategori Skripsi Bagi Mahasiswa Sistem Informasi
}

\author{
Renny Puspita Sari, Enricho Rasimin \\ Fakultas Ilmu Pengetahuan Alam, Sistem Informasi, Universitas Tanjungpura, Pontianak, Indonesia \\ Email: 1 rennysari.untan@ gmail.com, ${ }^{2}$ enrichoshen@ student.untan.ac.id \\ Submitted: 11/05/2021; Accepted: 27/05/2021; Published: 30/05/2021
}

\begin{abstract}
Abstrak-SPK atau biasanya yang disebut dengan Sistem Pendukung Keputusan merupakan sebuah sistem untuk merekomendasi keputusan dengan menggunakan data yang sudah ada, di Universitas Tanjungpura pada Fakultas Matematika dan Ilmu Pengetahuan lebih tepatnya prodi Sistem Informasi yang sekarang mempunyai mahasiswa/i sekitar 200 lebih dimana mahasiswa/i disana masih sering kebingungan untuk mengangkat judul skripsi apa yang mereka inginkan oleh karena itu peneliti akan membuat sistem yang dapat merekomendasi kategori skripsi apa yang lebih bagus digunakan pada prodi Sistem Informasi ini menggunakan metode SAW, sehingga mahasiswa/i bisa mengetahui kategori skripsi apa yang sesuai untuk mahasiswa/i tersebut. Dikarenakan sistem memakai nilai mata kuliah sebagai data untuk membuat keputusan oleh sebab itu akurasi dari sistem tersebut bisa melebihi $90 \%$.
\end{abstract}

Kata Kunci: SPK; Sistem Informasi; Mahasiswa; Skripsi; SAW

Abstract-SPK or usually called the Decision Support System is a system for recommending decisions using data, at Tanjungpura University, Faculty of Mathematics and Science, more precisely is Information Systems, which is now has more than 200 students where students are there still often confused to lift the title of what thesis they want, therefore I will create a system that can recommend what thesis is better used in this Information Systems study program using the SAW method, so that students can find out what thesis category is suitable for these students. Because the system uses course scores as data to make decisions, the accuracy of the system can exceed $90 \%$.

Keywords: DSS; Information System; College Student; Thesis; SAW

\section{PENDAHULUAN}

Di zaman sekarang dimana semua serba menggunakan internet, Internet (kependekan dari interconnectionnetworking) secara harfiah ialah sistem global dari seluruh jaringan komputer yang saling terhubung menggunakan standar Internet[1], dimana teknologi mempunyai peran untuk membantu manusia untuk melakukan tugas, oleh karena itu SPK atau Sistem Pendukung Keputusan merupakan sistem informasi interaktif yang menyediakan informasi, pemodelan, dan pemanipulasian data yang mempunyai peran untuk membantu manusia agar dapat membuat keputusan dengan lebih bijak dan cermat dengan menggunakan data yang sudah ada[2]. Dengan adanya bantuan SPK ini mahasiswa/i akan dimudahkan dalam pengambilan keputusan, keputusan yang pasti akan diambil oleh mahasiswa adalah penentuan kategori judul skripsi dimana keputusan bisa di katakan sulit dikarenakan mahasiswa/i ingin cepat lulus tetapi juga tidak ingin mengangkat judul yang tidak sesuai dengan prospek mahasiswa/i tersebut oleh karena itu peneliti akan membuat sistem pendukung keputusan yang akan merekomendasikan kategori judul skripsi bagi mahasiswa/i dengan metode SAW.

Pada zaman akhir 1950 sampai dengan awal 1960. Carnegie Institute of Technology menemukan sebuah metode untuk pengambilan keputusan untuk suatu organisasi hal itu yang kita kenal dengan namanya spk, hasil dari temuan Carnegie Institute of Technology tersebut, MIT atau Massachusetts Institute of Technology mengimplementasikan hal tersebut ke dalam komputer[3], terdapat beberapa penelitan tentang Sistem Pendukung Keputusan diantaranya adalah penelitian dari Ari Rahayu yang berjudul Sistem Pendukung Keputusan Pemilihan Mata Kuliah Pilihan Dengan Metode Topsis Topsis[4] terdapat penelitian lainnya yang berjudul Sistem Pendukung Keputusan Pemilihan Kategori Skripsi Bagi Mahasiswa Sistem Informasi oleh Iwan Laengge[5], dkk dan penelitian lainnya yang berjudul Sistem Pendukung Keputusan penentu Dosen Penguji Dan Pembimbing Tugas Akhir Menggunakan Fuzzy Multiple Attribute Decision Making dengan Simple Additive Weighting (Studi Kasus: Jurusan Teknik Informatika Uin Sgd Bandung) oleh Ian Septiani[6], dkk oleh karena itu peneliti ingin menyempurnakan penelitian sebelumnya dengan topik Sistem Pendukung keputusan untuk membuat pemilihan kategori skripsi dengan menggunakan metode SAW. Penggunakan metode SAW ini dipilih karena SAW merupakan metode yang mudah dipahami dan banyak digunakan.

SAW yang biasa juga disebut dengan Simple Additive Weighting, merupakan metode yang termasuk ke dalam keluarga Multiple Attribute Decision Making, konsep dasar SAW ini adalah mencari penjumlahan terbobot dari rating kinerja dari setiap alternatif di semua atribut. Metode SAW ini mempunyai cost dan benefit dimana benefit adalah nilai terbesar yang terbaik sedangkan cost adalah nilai kecil yang terbaik. Hasil dari metode SAW ini akan tersusun dari perangkingan, dimana menggunakan ranking peringkat ini akan membuat rekomendasi keputusan yang disediakan menjadi lebih akurat dikarenakan semua sudah dihitung berdasarkan nilai kriteria, nilai sub kriteria dan nilai bobot. Dikarenakan metode SAW atau Simple Additive Weighting menggunakan sistem perangkingan yang membuat hasil yang ada menjadi mudah dimengerti dan cara hitung Simple Additive Weighting ini bisa dibilang simpel dikarenakan keputusan ke suatu skala dapat dibandingkan dengan alternatif 
yang ada sehingga orang awam menjadi mengerti, oleh karena itu metode SAW atau Simple Additive Weighting banyak digunakan orang - orang yang dimana metode SAW tersebut diharapkan mampu memberikan keputusan yang efisien.

Metode SAW ini akan menentukan perangkingan dari setiap jenis skripsi yang ada di prodi Sistem Informasi yang berada pada Fakultas Ilmu Pengetahuan Alam Universitas Tanjungpura yang berada di Kota Pontianak Kalimantan Barat Indonesia, dimana di prodi Sistem Informasi UNTAN ini memiliki 3 jenis skripsi yaitu Analisis dan Desain Manajemen Sistem Informasi, Administrasi Basis Data, Pengembangan Aplikasi. Analisis dan Desain Manajemen Sistem Informasi ini menjelaskan tentang analisis suatu perusahaan yang telah menggunakan Sistem Informasi dan Manajemen Sistem Informasi dengan menggunakan metode yang sudah ada, Administrasi Basis Data ini akan menjelaskan cara memining data dengan memanfaatkan algoritma sehingga data bisa digunakan atau diurutkan dengan mudah sehingga user bisa mengetahui data - data apa saja yang sudah dimilikinya, basis data juga akan membuat gudang data agar semua data yang ingin digunakan bisa dicari di tempat tersebut. Pengembangan Aplikas yaitu mahasiswa/i akan membuat aplikasi atau mengembangkan aplikasi yang sudah ada agar aplikasi itu dapat membantu user untuk memudahkan pekerjaan nya, aplikasi ini bisa berbentuk desktop, web, maupun mobile. Sistem Informasi ini mempunyai cakupan yang luas dimana mahasiswa/i Sistem Informasi dituntut untuk menguasai dari bidang analisis, manajemen, data hingga pembuatan software yang bisa digunakan diberbagai platform.

Dengan adanya Karya Tulis Ilmiah ini diharapkan sistem dapat menyelesaikan permasalahan mahasiswa/i untuk memilih kategori judul skripsi agar mahasiswa/i bisa lulus tepat waktu. Sistem dapat melakukan perangkingan agar pembuat keputusan bisa memilih antara ranking 1 sampai 3. Sistem juga dapat memperlihatkan histori agar pembuat keputusan bisa melihat rekomendasi apa saja yang telah dibuat oleh sistem.

\section{METODE PENELITIAN}

\subsection{Tahapan Penelitan}

Penelitan ini menjalani beberapa tahap, tahap yang diperlukan sebagai berikut, Pertama data yang diperlukan sudah ada di dalam buku pedoman tahun ajaran 2018 - 2019, dimana pada buku tersebut dikatakan bahwa ada 3 jenis kategori skripsi yaitu Analisa dan Desain Manajemen Sistem Informasi, administrasi Basis Data, Pengembangan Aplikasi. Setelah itu, 3 jenis skripsi tersebut menjadi alternatif untuk membuat sistem pendukung keputusan. Sistem Pendukung Keputusan secara umum didefinisikan sebagai sebuah sistem yang mampu memberikan kemampuan baik kemampuan pemecahan masalah maupun kemampuan pengkomunikasian untuk masalah semi terstruktur. Secara khusus Sistem Pendukung Keputusan didefinisikan sebagai sebuah sistem yang mendukung kerja seorang manajer maupun sekelompok manajer dalam memecahkan masalah semi-terstruktur dengan cara memberikan informasi ataupun usulan menuju pada keputusan tertentu[7]. Setelah membuat SPK atau sistem pendukung keputusan maka bisa dibuat untuk kategori skripsi dimana skripsi Menurut Komaruddin skripsi berasal dari bahasa Latin, scriptio, hal menulis, karangan tertulis tentang sesuatu, uraian, skripsi. Tulisan ilmiah sebagai salah satu syarat untuk mencapai peringkat atau gelar akademis tertentu. Sedangkan menurut kamus online Penulisan skripsi adalah "Karya ilmiah yang ditulis berdasarkan suatu hasil penelitian lapangan atau kajian pustaka dan dapat dipertahankan di depan ruang sidang dalam rangka penyelesaian studi strata 1 (S1)[8]". Tahap selanjut nya yaitu akan melakukan perhitungan dengan menggunakan SAW dengan melakukan perencanaan untuk tahap secara desain dan perhitungan. Setelah itu mahasiswa akan mencoba menguji sistem tersebut apakah sistem tersebut bisa merekomendasi kategori skripsi tersebut. Mahasiswa adalah siswa strata S1 dalam tahap perkembangannya digolongkan sebagai remaja akhir dan dewasa awal, yaitu usia 18-21 tahun dan 22-24 tahun. Pada usia tersebut mahasiswa mengalami masa peralihan dari remaja akhir ke dewasa. Pengertian mahasiswa menurut Dirjen Dikti adalah seseorang yang terdaftar di Perguruan Tinggi dan mengikuti jenjang semester berjalan[9]. Tahap selanjutnya mahasiswa sistem informasi akan membuat keputusan dimana sistem informasi menurut James O'Brien (2005) "sistem informasi adalah suatu kombinasi teratur apapun dari people (orang), hardware (perangkat keras), software (perangkat lunak), computer networks and data communications (jaringan komunikasi), dan database (basis data) yang mengumpulkan, mengubah dan menyebarkan informasi didalam suatu bentuk organisasi." Loudon (7:2002) "sistem informasi adalah komponen-komponen yang saling berhubungan dan bekerjasama untuk mengumpulkan, memproses, menyimpan dan mendistribusikan informasi untuk mendukung pengambilan keputusan, koordinasi, kontrol, analisis dan visualisasi dalam suatu organisasi."[10]. Tahap terakhir adalah membuat laporan penelitian.

\subsection{Multiple Attribute Decision Making (MADM)}

Multiple Attribute Decision Making (MADM) adalah suatu metode yang digunakan untuk mencari alternatif optimal dari sejumlah alternatif dengan kriteria tertentu sesuai dengan yang diperlukan. Inti dari MADM adalah menentukan bobot untuk setiap atribut, kemudian dilanjutkan dengan proses perangkingan yang digunakan untuk menyelesaikan alternatif yang sudah diberikan. Ada beberapa metode yang dapat digunakan untuk menyelesaikan masalah MADM salah satu nya adalah SAW atau Simple Additive Weighting (SAW)[11], [12]. 


\subsection{Metode Simple Additive Weighting (SAW)}

Menurut Fishburn dan MacCrimmon dalam (Munthe, 2013) Konsep dasar metode Simple Additive Weight (SAW) adalah mencari penjumlahan terbobot dari rating kinerja pada setiap alternatif pada semua atribut. Metode SAW memerlukan proses normalisasi matriks keputusan pada suatu skala yang akan dibandingkan dengan semua rating dari alternatif yang ada. Menurut (Asnawati dan Kanedi, 2012) "Kriteria penilaian dapat ditentukan sendiri sesuai dengan kebutuhan perusahaan"[13]. Berikut merupakan tahap perhitungan dari metode SAW mulai dari awal hingga sistem dapat mengeluarkan hasil akhir berupa perankingan.

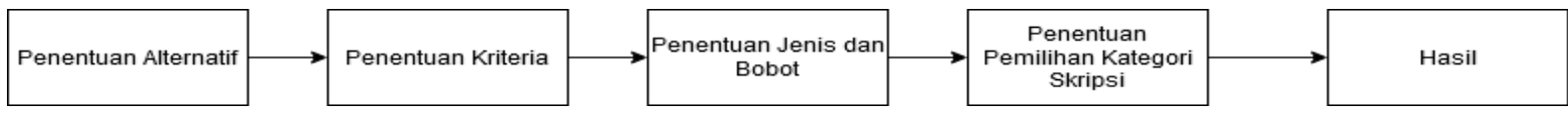

Gambar 1. Algoritma Metode SAW

Berikut rumus atau istilah yang diperlukan dalam menggunakan metode SAW:

1. Membentuk Matriks keputusan

$$
\mathrm{R}=\left[\begin{array}{lll}
r_{11} & r_{21} & r_{31} \\
r_{12} & r_{22} & r_{32} \\
r_{13} & r_{23} & r_{33}
\end{array}\right]
$$

2. Melakukan Normalisasi Matrik Keputusan

$$
r_{i j}=\left\{\begin{array}{c}
\frac{X_{i j}}{\operatorname{Max} X_{i j}} \text { Jikajadalahatributkeuntungan(benefit) } \\
\frac{\operatorname{MinX_{ij}}}{X_{i j}} \text { Jikajadalahatributbiaya }(\text { cost })
\end{array}\right.
$$

Keterangan :

$\mathrm{r}_{\mathrm{ij}} \quad=$ Rating kinerja ternormalisasi

Max = Nilai maksimum dari setiap baris dan kolom

Min = Nilai minimum dari setiap baris dan kolom

$\mathrm{X}_{\mathrm{ij}} \quad=$ Baris dan kolom dari matriks

3. Menghitung Preferensi

Dengan $r_{i j}$ adalah rating kinerja ternormalisasi dari alternatif Ai pada atribut $\mathrm{Cj} ; \mathrm{i}=1,2, \ldots \mathrm{m}$ dan $\mathrm{j}=1,2, \ldots, n$.

Keterangan :

$$
V_{i}=\sum_{j=i}^{n} w_{j} r_{i j}
$$

$\mathrm{Vi} \quad=$ Nilai akhir dari alternatif

$\mathrm{w}_{\mathrm{j}} \quad=$ Bobot yang telah ditentukan

$\mathrm{r}_{\mathrm{ij}} \quad=$ Normalisasi matriks

Terdapat beberapa langkah dalam penyelesaian metode Simple Additive Weighting (SAW)[14]-[17], sebagai berikut:

a. Menentukan kriteria-kriteria yang dijadikan acuan dalam pendukung keputusan yaitu $\mathrm{Ci}$.

b. Menentukan rating kecocokan setiap alternatif pada setiap kriteria.

c. Membuat matriks keputusan berdasarkan kriteria (Ci).

d. Kemudian melakukan normalisasi matriks berdasarkan persamaan yang disesuaikan dengan jenis atribut (atribut keuntungan maupun atribut biaya) sehingga diperoleh matriks ternormalisasi $r$.

e. Hasil akhir diperoleh dari proses perangkingan yaitu penjumlahan dari perkalian matriks ternormalisasi $r$ dengan vektor bobot sehingga diperoleh nilai terbesar yang dipilih sebagai alternatif terbaik (Ai) sebagai solusi.

\section{HASIL DAN PEMBAHASAN}

\subsection{Penerapan Metode SAW}

Perhitungan SAW atau Simple Additive Weighting dapat dilakukan untuk menentukan jenis kategori skripsi yang akan dikerjakan, dengan melakukan sistem pendukung keputusan, user atau yang akan mengambil keputusan akan sangat terbantu dikarenakan keputusan yang akan diambil telah dibantu oleh sistem yang dimana sistem itu telah didukung oleh data yang ada. Dalam melakukan perhitungan SPK atau sistem pendukung keputusan ada beberapa tahap yang perlu dikerjakan, tahap pertama yaitu perlu adanya alternatif dimana alternatif disini adalah keputusan yang akan diambil, alternatif tersebut harus lebih dari satu dikarenakan jika alternatif nya hanya satu maka alternatif itu yang pasti akan diambil. Di dalam kasus ini alternatif yang ada yaitu Analisa dan Desain Manajemen Sistem Informasi, Administrasi Basis Data, Pengembangan Aplikasi. Sedangkan Kriteria yaitu A1, A2, A3, A4. Semua data tersebut diambil dari buku pedoman akademik program S1 tahun ajaran 2018 - 2019. 


\subsubsection{Penentuan Alternatif}

Alternatif merupakan jenis keputusan yang akan diambil, dengan menggunakan SAW atau Simple Additive Weighting untuk mengambil keputusan, keputusan yang akan diambil merupakan keputusan menurut sistem adalah keputusan yang paling bagus.

Tabel 1. Alternatif

\begin{tabular}{cc}
\hline Alternatif & Nama \\
\hline 1 & Analisa dan Desain Manajemen Sistem Informasi \\
2 & Administrasi Basis Data \\
3 & Pengembangan Aplikasi \\
\hline
\end{tabular}

\subsubsection{Penentuan Kriteria}

Dalam pengambilan keputusan atau alternatif, perlu adanya kriteria untuk membuat keputusan yang tepat, ada beberapa kriteria dalam kasus penentuan kategori skripsi untuk mahasiswa sistem informasi, berikut kriteria nya:

a. A1

Tabel 2. Kriteria A1

\begin{tabular}{ccc}
\hline Kriteria & Sub-Kriteria & Nilai Kriteria \\
\hline A1 & Perencanaan Strategi Sistem dan & $\mathrm{A}=5, \mathrm{~B}=4, \mathrm{C}=3, \mathrm{D}=2, \mathrm{E}=1$ \\
& Teknologi Informasi & \\
Bisnis Intelijen & $\mathrm{A}=5, \mathrm{~B}=4, \mathrm{C}=3, \mathrm{D}=2, \mathrm{E}=1$ \\
& Teknologi Bergerak & $\mathrm{A}=5, \mathrm{~B}=4, \mathrm{C}=3, \mathrm{D}=2, \mathrm{E}=1$ \\
\hline
\end{tabular}

b. A2

Tabel 3. Kriteria A2

\begin{tabular}{ccc}
\hline Kriteria & Sub-Kriteria & Nilai Kriteria \\
\hline A2 & Manjemen Rantai Pasok & $\mathrm{A}=5, \mathrm{~B}=4, \mathrm{C}=3, \mathrm{D}=2, \mathrm{E}=1$ \\
& Data Mining & $\mathrm{A}=5, \mathrm{~B}=4, \mathrm{C}=3, \mathrm{D}=2, \mathrm{E}=1$ \\
& Pemrograman Web 1 & $\mathrm{A}=5, \mathrm{~B}=4, \mathrm{C}=3, \mathrm{D}=2, \mathrm{E}=1$ \\
\hline
\end{tabular}

c. A3

Tabel 4. Kriteria A3

\begin{tabular}{ccc}
\hline Kriteria & Sub-Kriteria & Nilai Kriteria \\
\hline A3 & Manajemen Hubungan Pelanggan & $\mathrm{A}=5, \mathrm{~B}=4, \mathrm{C}=3, \mathrm{D}=2, \mathrm{E}=1$ \\
& Data Warehouse & $\mathrm{A}=5, \mathrm{~B}=4, \mathrm{C}=3, \mathrm{D}=2, \mathrm{E}=1$ \\
& Pemrograman Web 2 & $\mathrm{A}=5, \mathrm{~B}=4, \mathrm{C}=3, \mathrm{D}=2, \mathrm{E}=1$ \\
\hline
\end{tabular}

d. A4

Tabel 5. Kriteria A4

\begin{tabular}{ccc}
\hline Kriteria & Sub-Kriteria & Nilai Kriteria \\
\hline A4 & Arsitektur Perusahaan & $\mathrm{A}=5, \mathrm{~B}=4, \mathrm{C}=3, \mathrm{D}=2, \mathrm{E}=1$ \\
& Sistem Pendukung Keputusan & $\mathrm{A}=5, \mathrm{~B}=4, \mathrm{C}=3, \mathrm{D}=2, \mathrm{E}=1$ \\
& Pemrograman Berorientasi Objek & $\mathrm{A}=5, \mathrm{~B}=4, \mathrm{C}=3, \mathrm{D}=2, \mathrm{E}=1$ \\
\hline
\end{tabular}

\subsubsection{Penentuan Jenis dan Bobot}

Dengan menggunakan metode SAW atau Simple Additive Weighting perlu menggunakan bobot, oleh karena itu maka ditambahkan bobot sedangkan jenis, di dalam SAW atau Simple Additive Weighting ada 2 jenis kriteria, yaitu kriteria cost dan kriteria benefit. Cost adalah nilai yang semakin kecil maka itu yang akan diambil dikarenakan itu yang paling bagus, sedangkan Benefit adalah nilai yang semakin tinggi maka itu yang akan diambil dikarenakan itu yang paling bagus, untuk kasus menentukan kategori untuk skripsi dengan menggunakan metode SAW atau Simple Additive Weighting yang berpaku dengan nilai maka hanya akan menggunakan Benefit dikarenakan nilai yang semakin tinggi maka itu yang paling bagus.

Tabel 6. Jenis dan Bobot

\begin{tabular}{ccc}
\hline Kriteria & Jenis Kriteria & Bobot Kriteria \\
\hline A1 & Benefit & $7 \%$ \\
A2 & Benefit & $7 \%$ \\
A3 & Benefit & $7 \%$ \\
A4 & Benefit & $7 \%$ \\
\hline
\end{tabular}




\subsubsection{Perhitungan Pemilihan Kategori Skripsi}

a. Pemberian Nilai Alternatif

Contoh kasus untuk memilih kategori skripsi, sebelum menghitung perlu untuk memberikan nilai alternatif. Dalam kasus ini jika nilai mempunyai + maka akan dinaikkan ke atas, contoh nya seperti B+ maka akan menjadi A.

Tabel 7. Perhitungan Pemilihan Kategori Skripsi

\begin{tabular}{ccccc}
\hline \multirow{2}{*}{ Alternatif } & \multicolumn{4}{c}{ Kriteria } \\
\cline { 2 - 5 } & A1 & A2 & A3 & A4 \\
\hline Analisa dan Desain Manajemen Sistem & A & A & C & B \\
Administrasi Basis Data & B & D & A & A \\
Pengembangan Aplikasi & B+ & A & B+ & D+ \\
\hline
\end{tabular}

Setelah diberikan nilai kemudian di normalisasi dalam bentuk angka sesuai dengan penentuan nilai kriteria.

Tabel 8. Normalisasi Nilai Alternatif

\begin{tabular}{ccccc}
\hline \multirow{2}{*}{ Alternatif } & \multicolumn{4}{c}{ Kriteria } \\
\cline { 2 - 5 } & A1 & A2 & A3 & A4 \\
\hline Analisa dan Desain Manajemen Sistem & 5 & 5 & 3 & 4 \\
Administrasi Basis Data & 4 & 2 & 5 & 5 \\
Pengembangan Aplikasi & 5 & 5 & 5 & 3 \\
\hline
\end{tabular}

b. Pembuatan Matriks Keputusan

Matriks akan memudahkan untuk menghitung keputusan.

5534

$\mathbf{R}=4255$

5553

c. Normalisasi Kriteria

Melakukan normalisasi kriteria dengan menggunakan rumus dalam metode SAW

1. Kriteria A1

$$
\mathrm{R}_{11}=\frac{5}{\max (5,4,5)}=\frac{5}{5}=1 \quad \mathrm{R}_{12}=\frac{4}{\max (5,4,5)}=\frac{4}{5}=0.8 \quad \mathrm{R}_{13}=\frac{5}{\max (5,4,5)}=\frac{5}{5}=1
$$

\section{Kriteria A2}

$$
\mathrm{R}_{21}=\frac{5}{\max (5,2,5)}=\frac{5}{5}=1 \quad \mathrm{R}_{22}=\frac{2}{\max (5,2,5)}=\frac{4}{5}=0.4 \quad \mathrm{R}_{23}=\frac{5}{\max (5,2,5)}=\frac{5}{5}=1
$$

3. Kriteria A3

$$
\mathrm{R}_{31}=\frac{3}{\max (3,5,5)}=\frac{5}{5}=0.6 \mathrm{R}_{32}=\frac{5}{\max (3,5,5)}=\frac{5}{5}=1 \quad \mathrm{R}_{33}=\frac{5}{\max (3,5,5)}=\frac{5}{5}=1
$$

4. Kriteria A4

$$
\mathrm{R}_{31}=\frac{4}{\max (4,5,3)}=\frac{4}{5}=0.8 \mathrm{R}_{32}=\frac{5}{\max (4,5,3)}=\frac{5}{5}=1 \quad \mathrm{R}_{33}=\frac{3}{\max (4,5,3)}=\frac{5}{5}=0.6
$$

d. Melakukan Perangkingan

Melakukan perangkingan untuk mengetahui hasil akhir dari pemilihan alternatif keputusan.

$\mathrm{V}_{11}=(1)(0.07)+(1)(0.07)+(0.6)(0.07)+(0.8)(0.07)=0,238$

$\mathrm{V}_{12}=(0,8)(0.07)+(0,4)(0.07)+(1)(0.07)+(1)(0.07)=0,224$

$\mathrm{V}_{13}=(0,33)(0.07)+(1)(0.07)+(0,33)(0.07)+(0,33)(0.07)=0,252$

e. Hasil Perangkingan

Tabel 9. Hasil Perangkingan

\begin{tabular}{cccc}
\hline No. & Alternatif & Nilai & Ranking \\
\hline 1 & Analisa dan Desain Manajemen Sistem Informasi & 0,238 & Ranking 2 \\
2 & Administrasi Basis Data & 0,224 & Ranking 3 \\
3 & Pengembangan Aplikasi & 0,252 & Ranking 1 \\
\hline
\end{tabular}

\subsection{Rancangan Use Case Diagram}

Use Case diagram merupakan pemodelan untuk kelakuan atau behavior yang dimiliki sistem informasi yang akan dibuat. Use case digunakan untuk mengetahui fungsi apa saja ada di dalam sistem informasi dan siapa saja saja yang berhak menggunakan fungsi - fungi tersebut.[18] 
Pada Use Case tersebut Admin harus login terlebih dahulu untuk memasuki sistem web tersebut, setelah log in admin dapat menggunakan sistem tersebut yang mempunyai beberapa menu, seperti admin dapat mengubah profil seperti membuat password baru, mengubah alternatif yang ada seperti menambah alternatif baru, mengedit alternatif yang lama, mengubah kriteria \& sub kriteria atau menambahkan kriteria \& subkriteria, mengubah nilai bobot dari kriteria \& subkriteria, admin juga dapat menguji sistem untuk melihat sistem tersebut sudah bisa jalan dengan benar atau tidak dan terakhir admin juga dapat log out, jika admin lupa password maka admin dapat menggunakan menu forgot password.

Untuk menggunakan sistem ini user harus juga log in ke sistem jika user lupa dengan password, user bisa menggunakan menu forgot password untuk bisa log in lagi, setelah log in user bisa mengubah profil seperti membuat password baru, user juga bisa menginput nilai agar dapat melihat rekomendasi sistem untuk judul skripsi tersebut, jika user ingin melihat rekomendasi sistem sebelumnya, user dapat menggunakan histori agar dapat melihat rekomendasi apa saja yang dilakukan oleh sistem tersebut, jika sudah selesai user dapat log out.

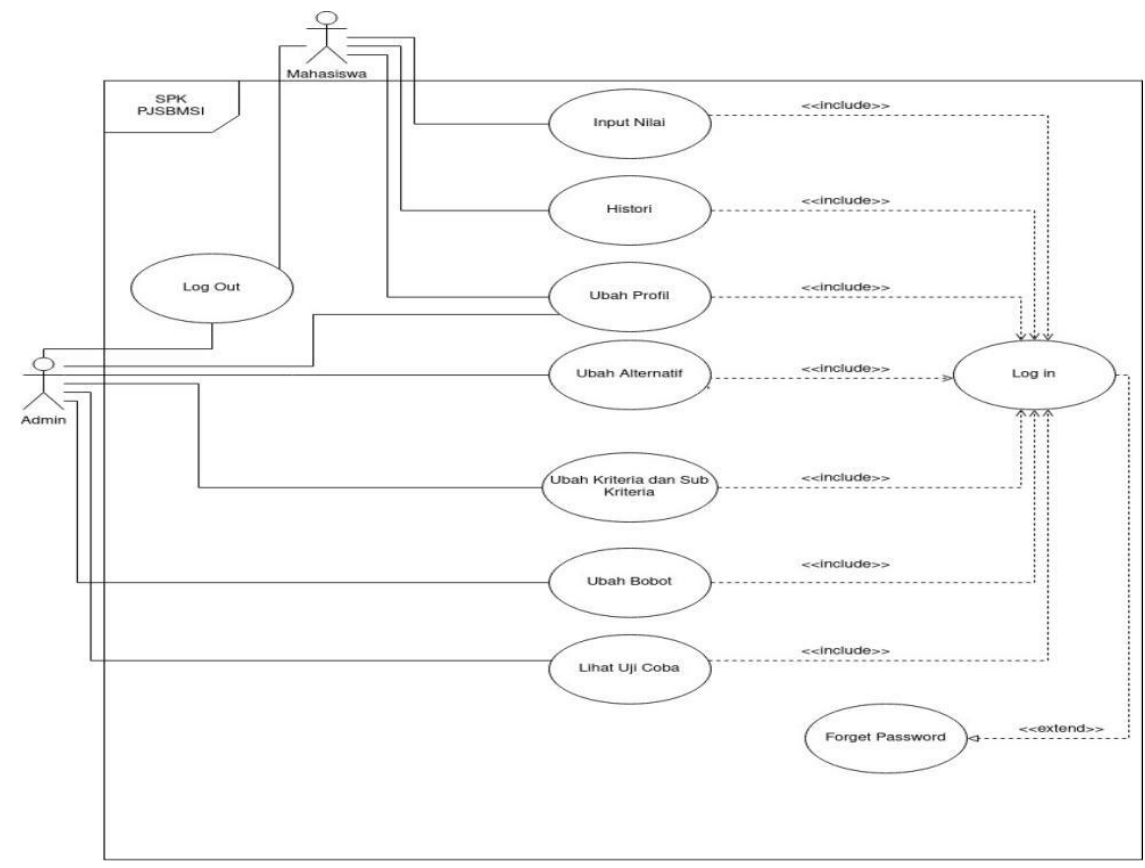

Gambar 2. Use Diagram Admin dan User

\subsection{Implementasi Program}

\section{a. Tampilan Halaman Log In}

Halaman Log In merupakan halaman awal untuk masuk ke sistem rekomendasi kategori skripsi, user dan admin harus masuk dulu atau log in untuk menggunakan sistem tersebut. Ini adalah tampilan halaman log in.

\section{b. Tampilan Profil Admin}

Halaman ini admin bisa mengubah nama dan NIP, admin juga bisa mengganti password. Ini adalah tampilan profil admin.

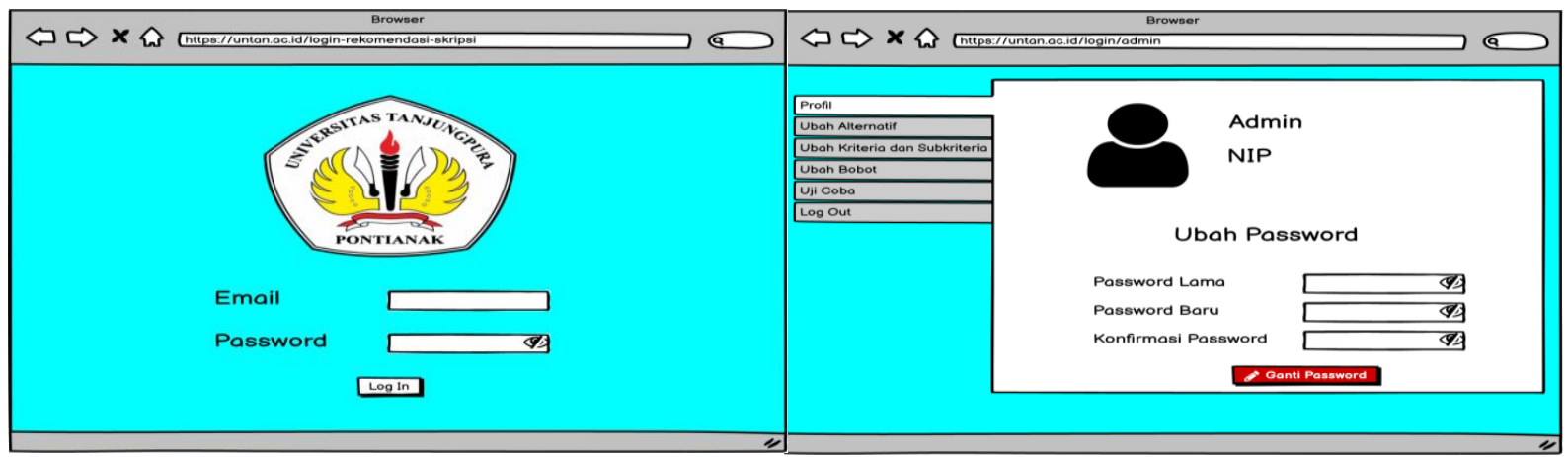

Gambar 3. Log In

Gambar 4. Profile Admin

\section{c. Tampilan Ubah Alternatif}

Halaman ini admin bisa mengubah alternatif, menambah alternatif dan mengedit alternatif. Ini adalah tampilan ubah alternatif. 


\section{d. Tampilan Ubah Kriteria dan Subkriteria}

Admin bisa mengubah kriteria \& subkriteria, mengedit kriteria \& subkriteria, menghapus kriteria \& subkriteria, menambah kriteria \& subkriteria dengan cara mencentang check box. Ini adalah tampilan kriteria dan subkriteria.

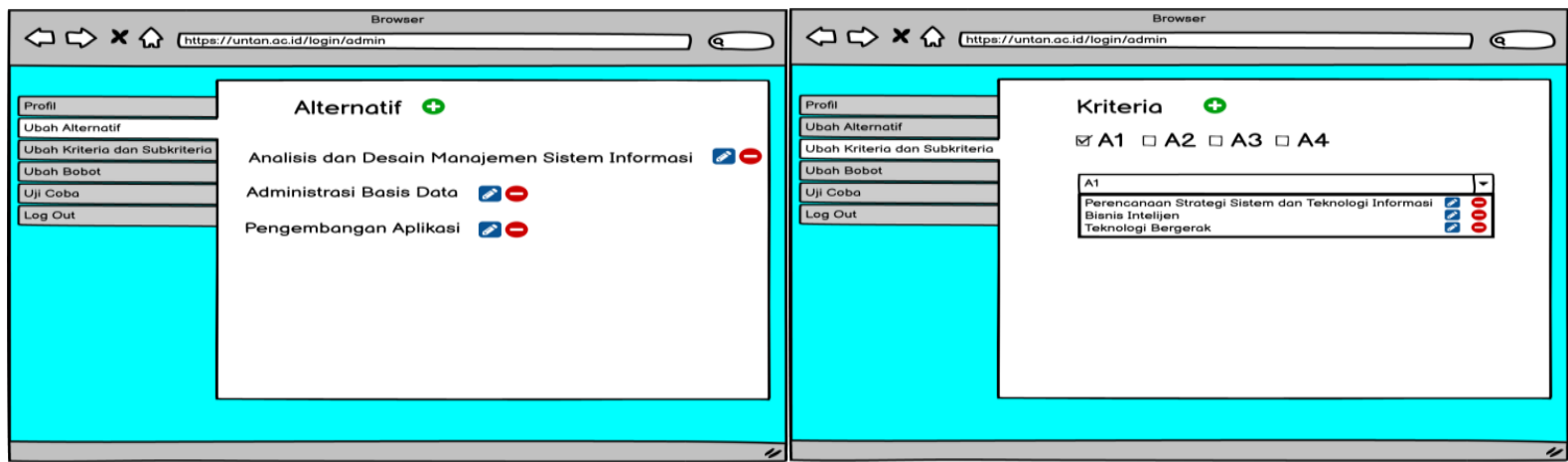

Gambar 5. Ubah Alternatif

Gambar 6. Kriteria dan Subkriteria

\section{e. Tampilan Ubah Bobot}

Admin bisa mengubah bobot dari kriteria \& subkriteria dengan cara mencentang check box. Ini adalah tampilan ubah bobot.

\section{f. Tampilan Uji Coba}

Admin bisa melakukan uji coba untuk mengetahui sistem tersebut apakah sudah benar atau tidak. Ini adalah tampilan ubah bobot.

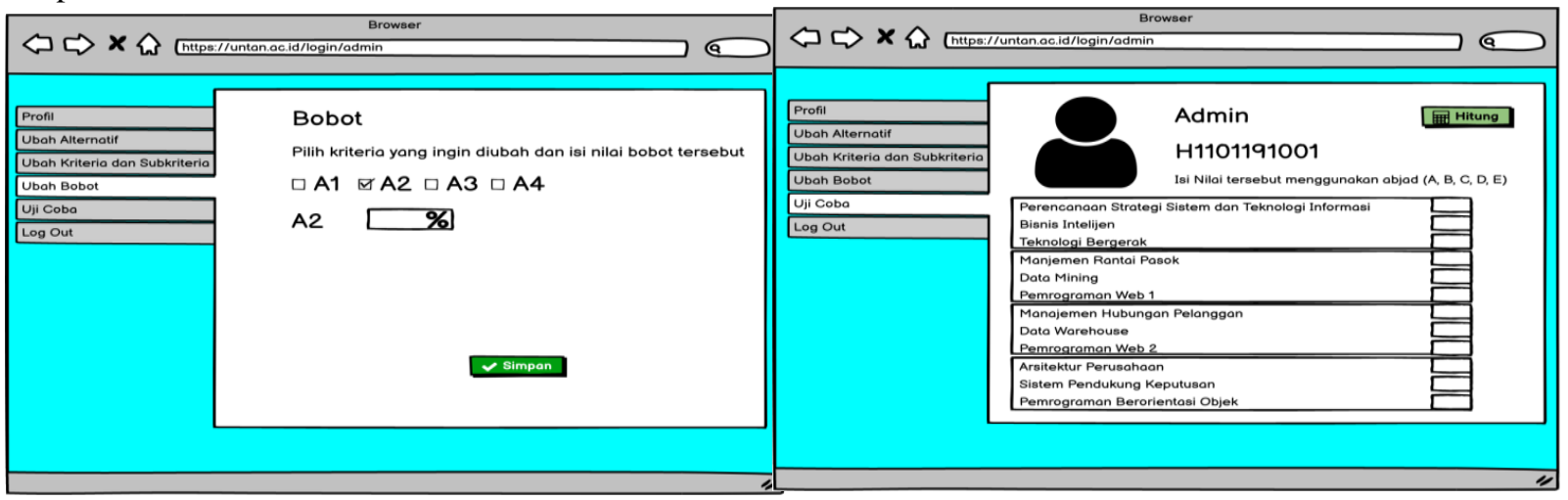

Gambar 7. Ubah Bobot

Gambar 8. Uji Coba

\section{g. Tampilan Hitung}

Setelah menekan tombol hitung maka, sistem akan menampilkan hasil dari perhitungan dan memberitahu hasil rekomendasi kategori skripsi. Ini adalah tampilan hitung.

\section{h. Tampilan Log Out}

Admin bisa untuk log out, jika ingin log out admin bisa menekan ya, jika tidak admin bisa menekan tidak untuk tidak keluar. Ini adalah tampilan log out.

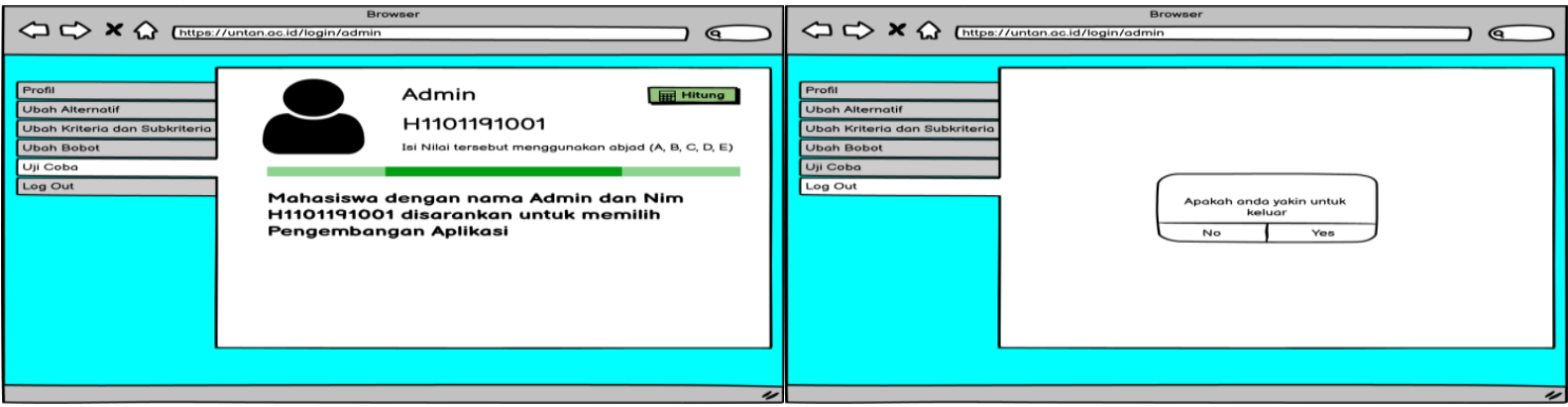

Gambar 9. Hitung

i. Tampilan Profil User

Gambar 10. Log Out

Halaman ini User bisa mengubah nama dan NIM, user juga bisa mengganti password. Ini adalah tampilan profil user. 


\section{j. Tampilan Input Nilai}

Halaman ini User bisa mengisi nilai dan user juga bisa menghitung. Ini adalah tampilan input nilai.

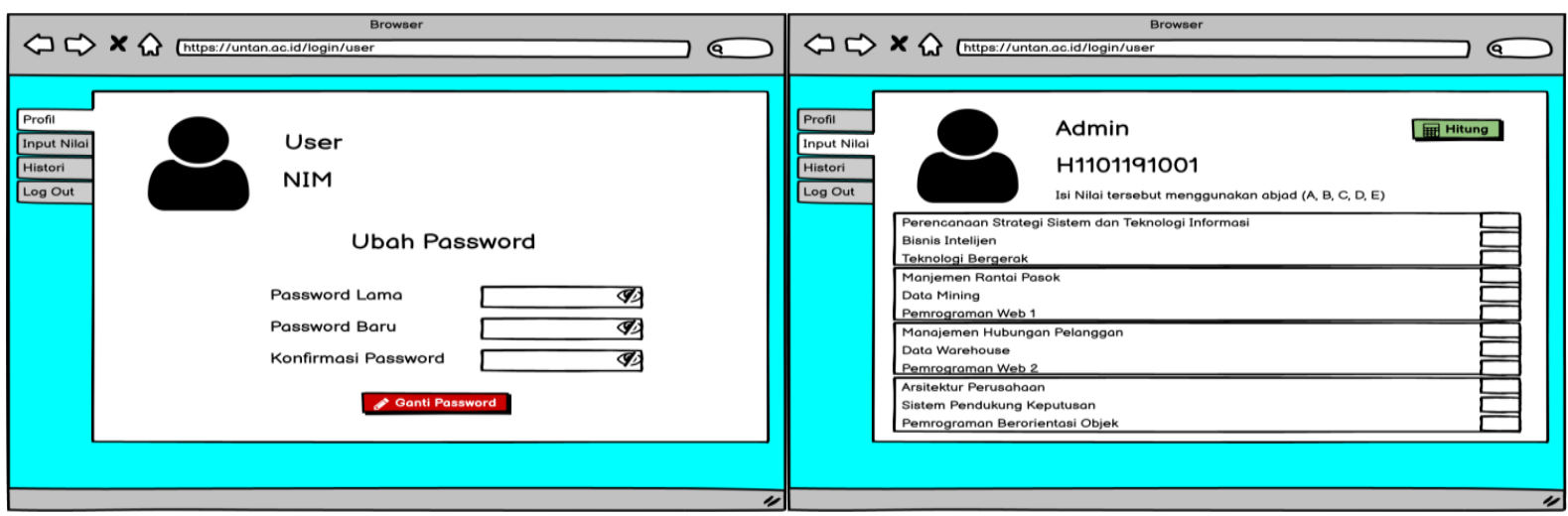

Gambar 11. Profil User

Gambar 12. Input Nilai

\section{k. Tampilan Hitung}

Setelah hitung, sistem akan menampilkan hasil rekomendasi kategori skripsi. Ini adalah tampilan hitung.

\section{Tampilan Histori}

User bisa melihat histori apa saja yang telah direkomendasikan oleh sistem, sistem akan mengurutkan hasil dari menurut tanggal.

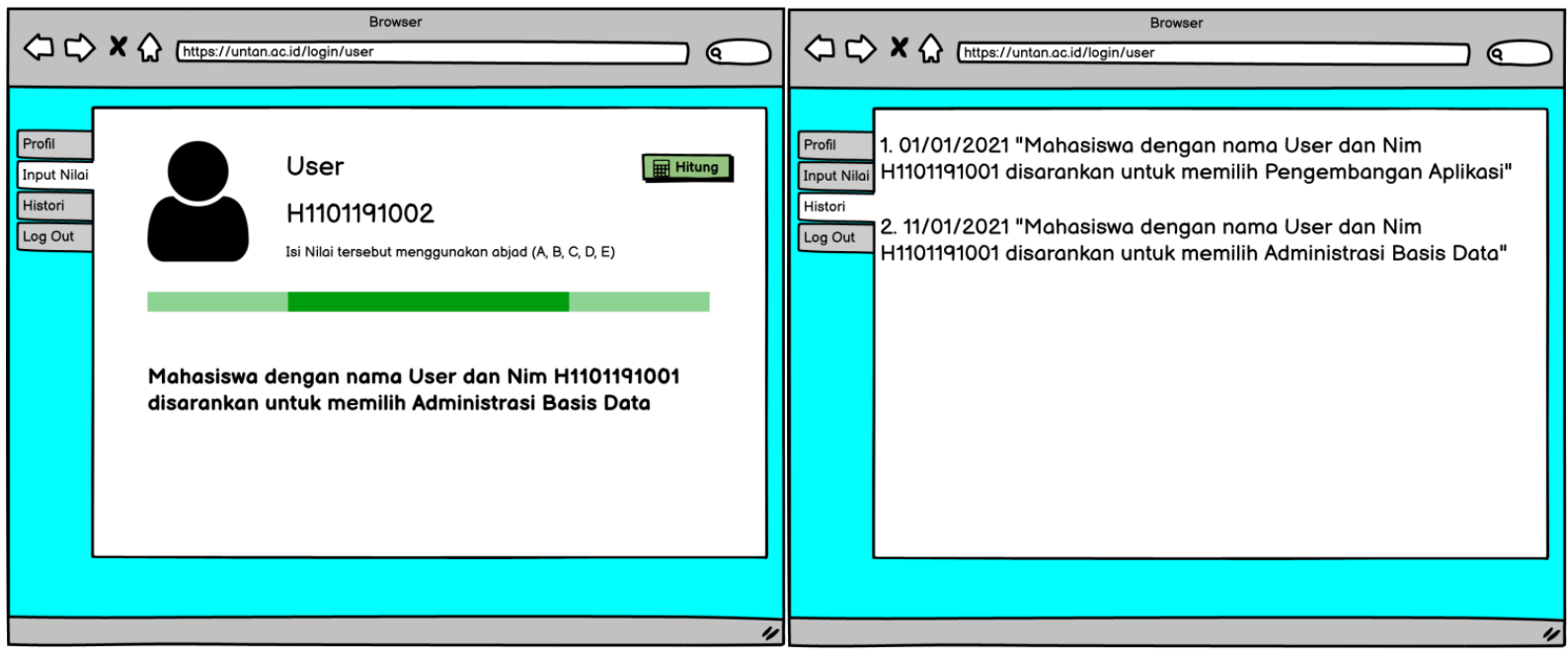

Gambar 13. Hitung

Gambar 14. Histori

\section{KESIMPULAN}

Dengan menggunakan SPK atau Sistem Pendukung Keputusan bisa untuk menghitung atau merekomendasikan kategori skripsi bagi mahasiswa Sistem Informasi, hasil perhitungan tersebut akan ditampilkan sesuai perangkingan. Sistem juga dapat menunjukkan hasil perhitungan sebelumnya yang dimana pengambil keputusan dapat membuat hal itu menjadi referensi. Dengan menggunakan SAW sistem tersebut dapat memproses hal itu secara cepat dikarenakan SAW mudah digunakan dan mudah dimengerti. Hanya memanfaatkan internet pengguna bisa melihat rekomendasi sistem dengan menuju ke halaman website, pengguna bisa mengakses sistem dimana dan kapan saja. Dengan adanya sistem tesebut mahasiswa/i yang berada di kampung halaman tetap bisa melihat perhitungan sistem supaya mahasiswa/i merencanakan kategori untuk judul skripsi kedepan.

\section{REFERENCES}

[1] B. Muslim and L. Dayana, "Sistem Informasi Peraturan Daerah (Perda) Kota Pagar Alam Berbasis Web," J. Ilm. Betrik, vol. 7, no. 01, pp. 36-49, 2016.

[2] L. Kristiyanti, A. Sugiharto, and H. A. W, "Sistem Pendukung Keputusan Pemilihan Pengajar Les Privat Untuk Siswa Lembaga Bimbingan Belajar Dengan Metode AHP (Studi Kasus LBB System Cerdas),” J. Masy. Inform., vol. 4, no. 7, pp. 39-47, 2011.

[3] Y. Reswan and D. A. Prabowo, "Sistem Pendukung Keputusan Evaluasi Kinerja Pegawai pada Dinas Pekerjaan Umum Bengkulu Selatan Menggunakan Simple Additive Weighting Method,” J. Media Infotama, vol. 14, no. 2, pp. 100-104, 
2018.

[4] A. Rahayu, "SISTEM PENDUKUNG KEPUTUSAN PEMILIHAN MATA KULIAH PILIHAN dengan METODE TOPSIS TOPSIS," e-conversion - Propos. a Clust. Excell., 2016.

[5] I. Laengge, H. F. Wowor, and M. D. Putro, "Sistem Pendukung Keputusan Dalam Menentukan Dosen Pembimbing Skripsi,”J. Tek. Inform., vol. 9, no. 1, 2016.

[6] I. Septiana, M. Irfan, A. R. Atmadja, and B. Subaeki, "Sistem Pendukung Keputusan Penentu Dosen Penguji Dan Pembimbing Tugas Akhir Menggunakan Fuzzy Multiple Attribute Decision Making dengan Simple Additive Weighting (Studi Kasus: Jurusan Teknik Informatika UIN SGD Bandung),” J. Online Inform., vol. 1, no. 1, p. 43, 2016.

[7] A. Nasution and K. Ulfa, "Sistem Pendukung Keputusan Kelayakan Pemberian Asuransi Jiwa Untuk Nelayan dengan Menggunakan Metode Vikor (Studi Kasus: Dinas Kelautan dan Perikanan Medan)," J. Sist. Komput. dan Inform., vol. 1, no. 3 , p. $220,2020$.

[8] A. N. Lumamuly and Y. Yuniwati, "Analisis Pemanfaatan Koleksi Referensi Di Perpustakaan Iain Salatiga Dalam Menunjang Penulisan Skripsi Mahasiswa Iain Salatiga,” J. Ilmu Perpust., vol. 6, no. 2, pp. 101-110, 2017.

[9] Q. B. Baloch, “No 主観的健康感を中心とした在宅高齢者における 健康関連指標に関する共分散構造分析 Title," vol. 11, no. 1, pp. 92-105, 2017.

[10] dan R. P. Agus Irawan, Anita Hasna, "Sistem Informasi Perdagangan Pada Pt Yoltan Sari Menggunakan Php Berbasis Web," Positif, vol. I, no. 2, pp. 8-15, 2016.

[11] Asep Syaputra, "Sistem Pendukung Keputusan Penerimaan Beasiswa Kurang Mampu Dengan Metode Simple Additive Weighting (Saw),” J. Ilm. Bin. STMIK Bina Nusant. Jaya Lubuklinggau, vol. 1, no. 2, pp. 50-55, 2019.

[12] T. Limbong et al., Sistem Pendukung Keputusan: Metode \& Implementasi. Medan: Yayasan Kita Menulis, 2020.

[13] F. Frieyadie, "Penerapan Metode Simple Additive Weight (Saw) Dalam Sistem Pendukung Keputusan Promosi Kenaikan Jabatan," J. Pilar Nusa Mandiri, vol. 12, no. 1, pp. 37-45, 2016.

[14] I. J. T. Situmeang, S. Hummairoh, S. M. Harahap, and Mesran, "Application of SAW ( Simple Additive Weighting ) for the Selection of Campus Ambassadors," IJICS (International J. Informatics Comput. Sci., vol. 5, no. 1, pp. 21-28, 2021.

[15] R. Y. Simanullang, Melisa, and Mesran, "TIN : Terapan Informatika Nusantara Sistem Pendukung Keputusan Penerima Bantuan Covid-19 Menggunakan Metode Simple Additive Weighting (SAW)," TIN Terap. Inform. Nusant., vol. 1, no. 9, pp. 2-9, 2021.

[16] M. R. Ramadhan, M. K. Nizam, and Mesran, "Penerapan Metode SAW (Simple Additive Weighting) Dalam Pemilihan Siswa-Siswi Berprestasi Pada Sekolah SMK Swasta Mustafa," TIN Terap. Inform. Nusant., vol. 1, no. 9, pp. 459-471, 2021.

[17] S. K. Simanullang and A. G. Simorangkir, "Sistem Pendukung Keputusan Penerimaan Calon Karyawan Menggunakan Metode Simple Additive Weighting," TIN Terap. Inform. Nusant., vol. 1, no. 9, pp. 472-478, 2021.

[18] A. Hendini, "Pemodelan Uml Sistem Informasi Monitoring Penjualan Dan Stok Barang," J. Khatulistiwa Inform., vol. 2, no. 9, pp. 107-116, 2016. 